\title{
Short term correction of anaemia with recombinant human erythropoietin and reduction of cardiac output in end stage renal failure
}

\author{
K P Morris, J R Skinner, S Hunter, M G Coulthard
}

\begin{abstract}
Children with end stage renal failure and anaemia have an increased cardiac index and often gross ventricular hypertrophy. The contribution of anaemia to these abnormalities is uncertain. Eleven children with end stage renal failure and anaemia (haemoglobin concentration $<90 \mathrm{~g} / \mathrm{l}$ ) were enrolled into a single blind, placebo controlled, crossover study to assess the cardiovascular effects of reversing anaemia using subcutaneous human recombinant erythropoietin (r-HuEpo). Each limb lasted 24 weeks; seven children completed both limbs of the study.
\end{abstract}

Haemoglobin increased with r-HuEpo, remaining above $100 \mathrm{~g} / \mathrm{l}$ for a mean of 11 weeks. Cardiac index fell as a result of a reduction in both left ventricular stroke volume and heart rate. Left ventricular end diastolic diameter also decreased. In five children left ventricular wall thickness and left ventricular mass decreased with r-HuEpo, but this failed to reach significance for the whole group.

Blood pressure did not change in six normotensive children completing an r-HuEpo limb; the decrease in cardiac index was therefore balanced by an increase in peripheral vascular resistance. Three children were taking antihypertensive treatment at the start of the study; one required an increase, and one a decrease, in treatment during the r-HuEpo limb.

Short term treatment with $\mathrm{r}-\mathrm{HuEpo}$ reduces cardiac index. A longer study is needed to determine whether this will, in time, result in a significant reduction in left ventricular hypertrophy.

(Arch Dis Child 1993; 68: 644-648)
Cardiovascular complications are the commonest cause of death in children with end stage renal failure. ${ }^{\prime}$ Children with end stage renal failure and anaemia frequently have an increased cardiac index and marked left ventricular hypertrophy, particularly affecting the interventricular septum. ${ }^{2}$ The relative contributions of anaemia and hypertension to these findings are uncertain; children on antihypertensive treatment have the most marked abnormalities, despite apparent optimal blood pressure control. ${ }^{2}$

Studies in adults with end stage renal failure have documented similar cardiac abnormalities and have assessed the cardiovascular effects of reversing anaemia by means of red cell transfusion or recombinant human erythropoietin ( $r$ HuEpo) administration. Neff et al documented a normalisation of cardiac index after serial transfusion, ${ }^{3}$ while Teruel and colleagues found a similar fall in cardiac index after four months' treatment with $\mathrm{r}-\mathrm{HuEpo},{ }^{4}$ with a reduction in left ventricular hypertrophy detectable by 12 months. ${ }^{5}$

There are no reports in children with end stage renal failure of cardiovascular changes occurring with r-HuEpo treatment. We have therefore assessed the cardiovascular effects of 24 weeks' $\mathrm{r}$-HuEpo treatment in a group of children with end stage renal failure and anaemia, using a single blind, placebo controlled crossover study design.

\section{Patients and methods}

Eleven children (nine boys, two girls) were enrolled into the study. Their median age was 6.7 years (range $2 \cdot 3-12 \cdot 3$ ), and median haemoglobin concentration $73 \mathrm{~g} / 1$ (range 42-81).

Table 1 Clinical details of the 11 children entering the study

Department of Paediatric Nephrology, Royal Victoria Infimary, Newcastle upon Tyne K P Morris

M G Coulthard

Department of Paediatric Cardiology, Freeman Hospital, Newcastle upon Tyne J R Skinner

$S$ Hunter

Correspondence to: Dr Malcolm Coulthard, Department of

Paediatric Nephrology, Royal Victoria Infirmary, Newcastle Victoria Infirmary,
upon Tyne NE1 4L.

Accepted 15 November 1992

\begin{tabular}{|c|c|c|c|c|c|c|c|}
\hline Patient No & Sex & $\begin{array}{l}\text { Age } \\
\text { (years) }\end{array}$ & $\begin{array}{l}\text { Haemoglobin } \\
(\mathrm{g} / \mathrm{l})\end{array}$ & $\begin{array}{l}\text { Duration of } \\
\text { dialysis } \\
\text { (years) }\end{array}$ & Mode of dialysis & Diagnosis & $\begin{array}{l}\text { Treatment for } \\
\text { hypertension }\end{array}$ \\
\hline \multicolumn{8}{|c|}{$\begin{array}{l}\text { Group I } \\
\text { (r-HuEpo/placebo) }\end{array}$} \\
\hline $\begin{array}{l}1 \\
2 \\
3 \\
4 \\
5 \\
6\end{array}$ & $\begin{array}{l}M \\
M \\
F \\
M \\
M \\
F\end{array}$ & $\begin{array}{l}10 \cdot 4 \\
2 \cdot 8 \\
4 \cdot 5 \\
3 \\
6 \cdot 4 \\
8 \cdot 9\end{array}$ & $\begin{array}{l}42 \\
72 \\
81 \\
80 \\
73 \\
66\end{array}$ & $\begin{array}{l}3 \cdot 2 \\
2 \cdot 5 \\
3 \cdot 8 \\
1 \cdot 7 \\
3 \cdot 1 \\
0 \cdot 4\end{array}$ & $\begin{array}{l}\text { PROD } \\
\text { PROD } \\
\text { PROD } \\
\text { PROD } \\
\text { Haemodialysis } \\
\text { PROD }\end{array}$ & $\begin{array}{l}\text { Familial HUS } \\
\text { Dysplasia } \\
\text { Dysplasia } \\
\text { Congenital nephrotic syndrome } \\
\text { PUV } \\
\text { Unknown }\end{array}$ & $\begin{array}{l}\text { Yes } \\
\text { No } \\
\text { No } \\
\text { Yes } \\
\text { No } \\
\text { Yes }\end{array}$ \\
\hline $\begin{array}{l}\text { Group 2 } \\
\text { (Placebo/r-H }\end{array}$ & HuEpo & & & & & & \\
\hline $\begin{array}{r}7 \\
8 \\
9 \\
10 \\
11\end{array}$ & $\begin{array}{l}\mathbf{M} \\
\mathbf{M} \\
\mathbf{M} \\
\mathbf{M} \\
\mathbf{M}\end{array}$ & $\begin{array}{r}12 \cdot 3 \\
8 \cdot 8 \\
6 \cdot 7 \\
2 \cdot 3 \\
8 \cdot 8\end{array}$ & $\begin{array}{l}76 \\
68 \\
76 \\
64 \\
75\end{array}$ & $\begin{array}{l}0 \cdot 4 \\
0 \\
3 \cdot 2 \\
1 \\
7 \cdot 9\end{array}$ & $\begin{array}{l}\text { PROD } \\
\text { None } \\
\text { PROD } \\
\text { PROD } \\
\text { PROD }\end{array}$ & $\begin{array}{l}\text { FSGS } \\
\text { Reflux associated dysplasia* } \\
\text { Dysplasia } \\
\text { Infantile PCKD } \\
\text { PUV }\end{array}$ & $\begin{array}{l}\text { Yes } \\
\text { No } \\
\text { No } \\
\text { Yes } \\
\text { No }\end{array}$ \\
\hline
\end{tabular}

PROD=peritoneal rapid overnight dialysis; HUS=haemolytic uraemic syndrome; $P C K D=$ polycystic kidney disease; $P U V=$ posterior urethral valves; FSGS=focal segmental glomerulosclerosis; ` patient; with Duchenne muscular dystrophy. 


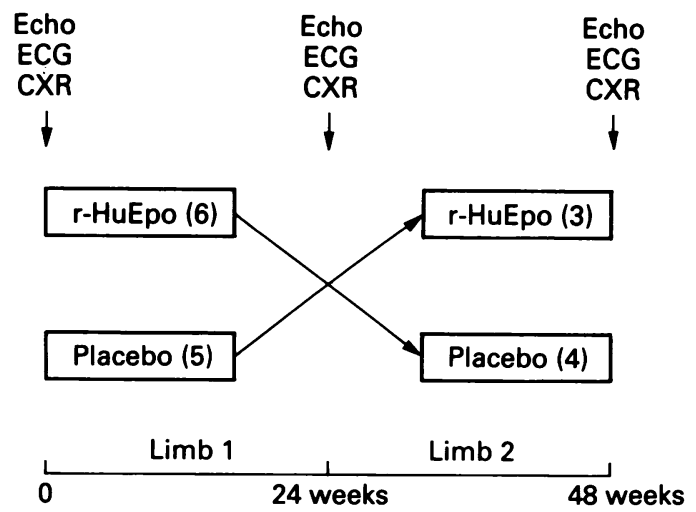

Figure 1 Basic study design (number of children). Echo= echocardiography; $E C G=$ electrocardiography; $C X R=$ chest radiography.

The range of underlying conditions and other clinical details are summarised in table 1 . Only Duchenne muscular dystrophy has recognised cardiac associations. A boy with Duchenne muscular dystrophy was included in the study because his baseline cardiac findings were compatible with the remainder of the group and it was felt that any short term changes in cardiac function were more likely to relate to $r-H u E p o$ treatment than to changes in his underlying disease process. Ten of the children were on dialysis at the time of the study; peritoneal rapid overnight dialysis (PROD) ${ }^{6}$ in nine cases and haemodialysis in one. Five children were receiving treatment for hypertension but all were normotensive, assessed with regular home blood pressure monitoring (Waeschle DS40).

The design was a single blind, placebo controlled, crossover study with two equal limbs of 24 weeks' duration (fig 1). Six children were allocated by stratified randomisation to receive

Table 2 Parameters measured on electrocardiography and echocardiography

\begin{tabular}{|c|c|}
\hline Electrocardiography & $\begin{array}{l}\text { P wave (II), Q wave (III, V5), R wave (aVR, V2, V5), S wave (V2, V5), } \\
\text { T wave (V2, V5), PR interval (II), QRS axis, QRS interval (V5), } \\
\text { QTc interval (V5), R/S ratio (V1, V5), RV5 +SV2 }\end{array}$ \\
\hline $\begin{array}{l}\text { Echocardiography } \\
\text { Cross sectional } \\
\text { M Mode }\end{array}$ & $\begin{array}{l}\text { Aortic root diameter (AoDiam) } \\
\text { Left atrial diameter } \\
\text { Interventricular septum (IVS) } \\
\text { Left ventricular posterior wall (LVPW) } \\
\text { Left ventricular end diastolic diameter (LVEDD) } \\
\text { Left ventricular end systolic diameter (LVES) }\end{array}$ \\
\hline $\begin{array}{l}\text { Doppler } \\
\text { CW } \\
\text { PW }\end{array}$ & $\begin{array}{l}\text { Aortic stroke distance (AoSD) } \\
\text { Peak diastolic flow (E and A waves) } \\
\text { Mitral and tricuspid flow }\end{array}$ \\
\hline
\end{tabular}

$\mathrm{PW}=$ pulsed wave $\mathrm{CW}=$ continuous wave.
r-HuEpo for 24 weeks followed by placebo, and five the reverse treatment order. Both the echocardiographer and the family were unaware of the treatment order in each child. Cardiac investigations were performed at baseline and then after 24 and 48 weeks. r-HuEpo (Recormon, Boehringer Mannheim) or placebo were administered subcutaneously twice weekly by the child or parent at home. The volume of all injections was fixed at $0.5 \mathrm{ml}$. r-HuEpo was commenced at $50 \mathrm{U} / \mathrm{kg} /$ week and increased in stepwise increments to a maximum of $400 \mathrm{U} / \mathrm{kg} /$ week by week 12 , thereafter adjusted to maintain a target haemoglobin concentration of 105-120 $\mathrm{g} / \mathrm{l}$.

Each child was assessed by clinical examination, chest radiography, electrocardiography, and echocardiography. Systolic and diastolic blood pressure was measured by auscultation using the largest cuff that could be applied to the upperarm. Thecardiothoracic ratiowas measured on each chest radiograph. A standard 12 lead electrocardiogram was performed in the semirecumbent position after five minutes rest (Marquette Instruments). A single experienced observer (JRS) performed all the echocardiograms using the same Hewlett Packard Sonos 1000 machine. Details of the echocardiographic methodology have been described in detail previously. ${ }^{2} A$ list of the electrocardiographic and echocardiographic measurements is shown in table 2 . From these the following were derived.

Equation 1.

$$
\text { Left ventricular stroke volume }(\mathrm{SV})=
$$
AoSD $\times \pi \times(\text { AoDiam } / 2)^{2}$

Equation 2.

Stoke index $(\mathrm{SI})=\mathrm{SV} /$ body surface area

Equation 3.

$$
\text { Cardiac output }(\mathrm{CO})=\mathrm{SV} \times \text { heart rate }
$$

Equation 4.

$$
\text { Cardiac index }=\mathrm{CO} / \text { body surface area }
$$

Equation 5.

$$
\text { Minute distance }=\mathrm{AoSD} \times \text { heart rate }
$$

Equation 6.

$$
\frac{0 \cdot 77\left\{(\text { LVEDD + LVPW + IVS })^{3}-(\text { LVEDD })^{3}\right\}+2 \cdot 4}{\text { Body }}
$$

Equation 7.

Fractional shortening $=($ LVEDD - LVESD $) /$ LVEDD

Equation 8.

\begin{tabular}{|c|c|c|c|c|c|c|}
\hline & \multicolumn{2}{|c|}{ Group 1: $r$-HuEpo/placebo $(n=4)$} & \multicolumn{2}{|c|}{ Group 2: placebolr-HuEpo $(n=3)$} & \multirow{2}{*}{$\begin{array}{l}\text { Overall mean effect } \\
\text { (\% change) of } r- \\
\text { HuEpo minus effect } \\
\text { of placebo }\end{array}$} & \multirow[b]{2}{*}{$p$ Value } \\
\hline & $\begin{array}{l}\text { After } 24 \text { weeks } \\
r-H u E p o\end{array}$ & $\begin{array}{l}\text { After } 24 \text { weeks } \\
\text { placebo }\end{array}$ & $\begin{array}{l}\text { After } 24 \text { weeks } \\
\text { placebo }\end{array}$ & $\begin{array}{l}\text { After } 24 \text { weeks } \\
r \text {-HuEpo }\end{array}$ & & \\
\hline $\begin{array}{l}\text { Cardiac index }\left(V \mathrm{~min} / \mathrm{m}^{2}\right) \\
\text { Heart rate (beats/min }) \\
\text { Stroke index }\left(\mathrm{ml}^{2} / \mathrm{m}^{2}\right) \\
\text { LVEDD }(\mathrm{cm}) \\
\text { LVESD }(\mathrm{cm}) \\
\text { Interventricular septum }(\mathrm{cm}) \\
\text { LVPW }(\mathrm{cm}) \\
\text { Left ventricular mass index }\left(\mathrm{g} / \mathrm{m}^{2}\right) \\
\text { Mean blood pressure }(\mathrm{mm} \mathrm{Hg}) \\
\text { Peripheral vascular resistance }(\mathrm{mm} \mathrm{Hg} / \mathrm{min} / \mathrm{l}) \\
\text { Shortening fraction }(\%) \\
\text { Cardiothoracic ratio }(\%) \\
\text { Aortic stroke distance } \\
\text { Minute distance }\end{array}$ & 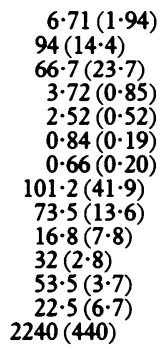 & $\begin{array}{c}9 \cdot 92(0 \cdot 77) \\
118 \cdot 3(19 \cdot 7) \\
84(19 \cdot 4) \\
3.88(0 \cdot 64) \\
2 \cdot 46(0 \cdot 64) \\
0 \cdot 90(0.22) \\
0 \cdot 75(0 \cdot 15) \\
120(48 \cdot 6) \\
65.3(8.4) \\
9 \cdot 2(2 \cdot 9) \\
37 \cdot 3(6 \cdot 7) \\
55(1 \cdot 8) \\
26 \cdot 3(3 \cdot 5) \\
3154(357)\end{array}$ & $\begin{array}{c}6 \cdot 65(0 \cdot 41) \\
106(6 \cdot 6) \\
67 \cdot 1(7.5) \\
3 \cdot 52(0 \cdot 07) \\
2 \cdot 16(0.06) \\
0.73(0 \cdot 10) \\
0.74(0.10) \\
87 \cdot 6(16 \cdot 5) \\
67 \cdot 3(11 \cdot 2) \\
13 \cdot 9(3 \cdot 8) \\
38 \cdot 3(2 \cdot 5) \\
47(3.6) \\
25 \cdot 7(0.5) \\
2580(447)\end{array}$ & $\begin{array}{l}5 \cdot 58(1 \cdot 56) \\
82 \cdot 3(12 \cdot 2) \\
55(8.7) \\
3.02(0.12) \\
1.98(0.17) \\
0.72(0.26) \\
0.72(0.26) \\
62 \cdot 9(11.8) \\
59 \cdot 3(11.8) \\
15 \cdot 8(8 \cdot 6) \\
34 \cdot 3(5.9) \\
42 \cdot 7(5.5) \\
20.4(3.4) \\
2074(634)\end{array}$ & $\begin{array}{l}-2 \cdot 29(-27) \\
-24 \cdot 0(-21) \\
-15 \cdot 1(-20) \\
-0 \cdot 31(-8) \\
-0 \cdot 04(-2) \\
-0 \cdot 04(-5) \\
-0 \cdot 06(-8) \\
-21 \cdot 3(-20) \\
+1 \cdot 3(+2) \\
+5 \cdot 2(+46) \\
-4 \cdot 7(-12) \\
-2 \cdot 7(-5) \\
-4 \cdot 4(-17) \\
-739(-25)\end{array}$ & $\begin{array}{l}0.01 \\
0.002 \\
0.03 \\
0.04 \\
0.52 \\
0.26 \\
0.57 \\
0.16 \\
0.96 \\
0.07 \\
0.11 \\
0.21 \\
0.01 \\
0.03\end{array}$ \\
\hline
\end{tabular}

Total peripheral vascular resistance $=$ mean blood pressure/cardiac output

Table 3 Echocardiographic, radiographic, and blood pressure changes at different stages in children completing both limbs of the study. Values are mean (SD)

LVEDD = left ventricular end diastolic diameter; LVESD=left ventricular end systolic diameter; LVPW=left ventricular posterior wall. 

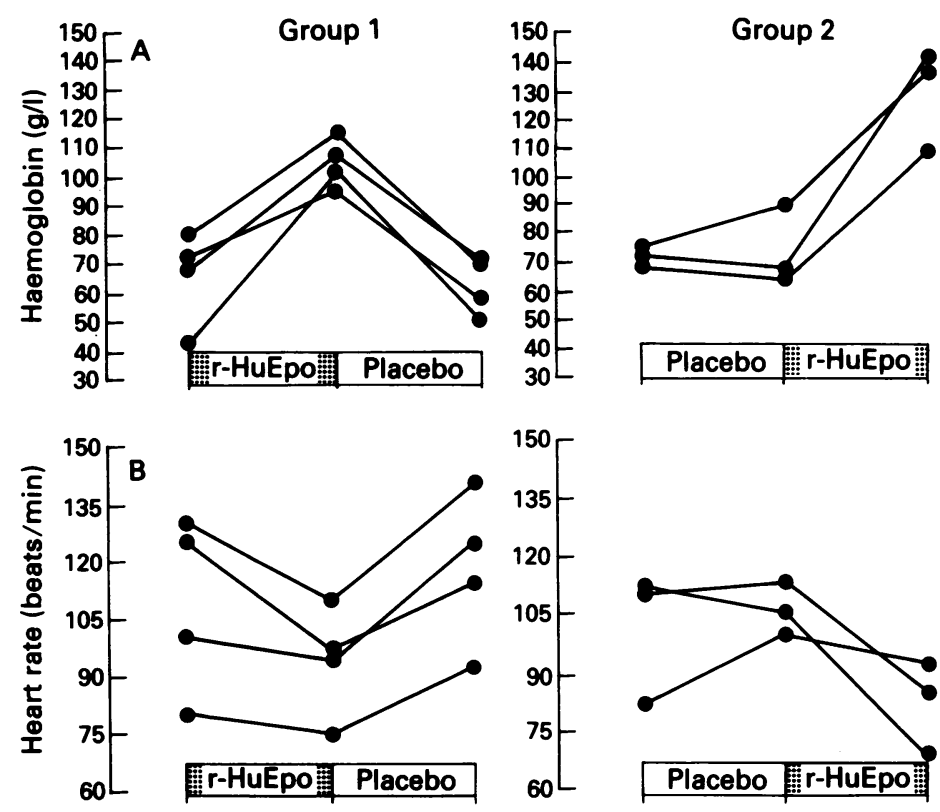

Placebo
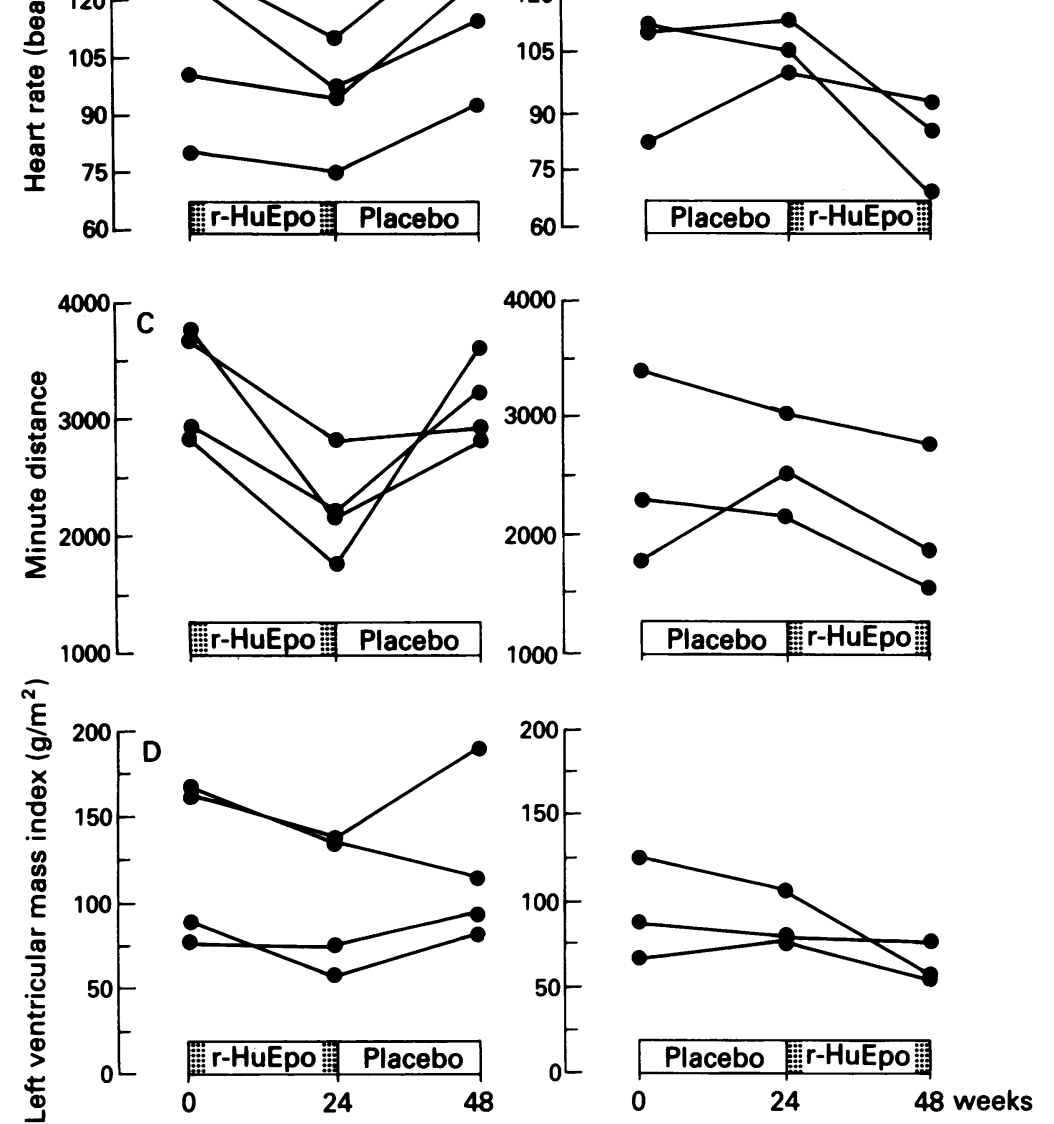

Figure 2 Individual changes in $(A)$ haemoglobin, $(B)$ heart rate, $(C)$ minute distance, and (D) left ventricular mass index in seven children completing both limbs of the study.

Left ventricular stroke volume is the product of the aortic flow integral on Doppler echocardiography (aortic stroke distance; AoSD), and the aortic cross sectional area, derived from aortic diameter measurement (AoDiam) on cross sectional echocardiography. In serial measurements over a limited period of time aortic diameter should change little, but considerable measurement error can occur. ${ }^{7}$ To avoid this potential source of error it is possible to follow changes in aortic stroke distance and minute distance, variables which correspond to stroke volume and cardiac output respectively, but avoid the variability of aortic diameter measurement.

Nine of the 11 children completed a 24 week period of r-HuEpo but only seven children completed both limbs of the study and were included in the analysis; three of the remaining four underwent renal transplantation during the study and one child died; this was related to his primary disease (patient 10). Treatment effects were calculated using statistical methods appropriate for the analysis of crossover trials, after excluding a significant period effect. ${ }^{8}$ To test for the presence of a treatment effect, the difference in any measured variable between week 24 (end of period 1) and week 48 (end of period 2) is calculated, and the mean difference found in group 1 compared with that found in group 2, using a standard two sample $t$ test. In the absence of a treatment effect the differences are the same, and the $t$ test non-significant.

\section{Results}

The relevant results are summarised in table 3 . $\mathrm{r}$-HuEpo produced a significant rise in mean haemoglobin from $69 \mathrm{~g} / \mathrm{l}$ to $115 \mathrm{~g} / \mathrm{l}$ after 24 weeks' treatment $(p=0.0001$ ) (fig $2 A)$. In association with this there was a significant fall in cardiac index, as a result of a fall in both left ventricular stroke index and heart rate (fig $2 \mathrm{~B}$ ). These findings were further supported by a fall in aortic stroke distance and minute distance (fig 2C).

Left ventricular end diastolic diameter and shortening fraction fell after $r$-HuEpo. Although in some patients there was a reduction in thickness of the interventricular septum and left ventricular posterior wall, this did not reach significance after 24 weeks' treatment. The same was true for estimated left ventricular mass index (fig 2D). No significant change was found in mitral or tricuspid valve diastolic flow after $\mathrm{r}$-HuEpo. Significant changes in the electrocardiogram after 24 weeks' treatment with $r$-HuEpo were an increase in the height of the T wave in V5 $(\mathrm{p}=0.002)$, and a prolongation of the QT interval ( $p=0.05)$, appropriate in relation to the reduction in heart rate. The mean cardiothoracic ratio fell from $51 \cdot 6 \%$ to $48.9 \%$ (nonsignificant). Subjectively there was a reduction in murmur intensity in five of the six children with audible ejection murmurs before r-HuEpo.

Three children on antihypertensive treatment completed an $\mathrm{r}-\mathrm{HuEpo}$ limb. One required an increase in treatment, one a reduction, and one no change. None of the remaining children needed to start antihypertensive treatment. Overall there was no significant change in systolic, diastolic or mean blood pressure related to r-HuEpo. Peripheral vascular resistance was not measured directly but was derived from mean blood pressure and cardiac output measurements (equation 8). Mean blood pressure did not change; the fall in cardiac output was therefore balanced by an appropriate rise in peripheral vascular resistance.

\section{Discussion}

Several studies have assessed the cardiac effects of $\mathrm{r}-\mathrm{HuEpo}$ in adult patients with end stage renal failure and anaemia. ${ }^{49-13}$ The majority have demonstrated a fall in cardiac index even after short treatment periods, as a result of a reduction in stroke index, ${ }^{511}$ heart rate, 9 or both..$^{10}$ Others, however, have found no change,,$^{12}$ or even an increase in cardiac index. ${ }^{13}$ Most short term 


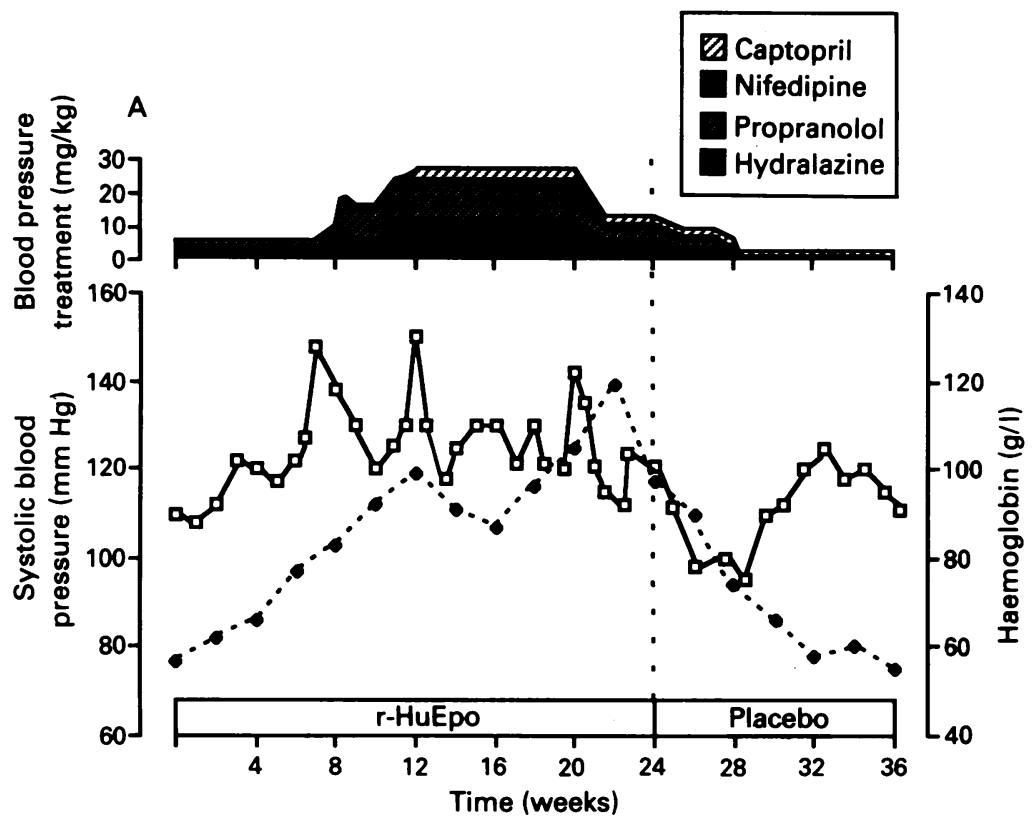

- O- Haemoglobin $\quad-0$-Systolic blood pressure

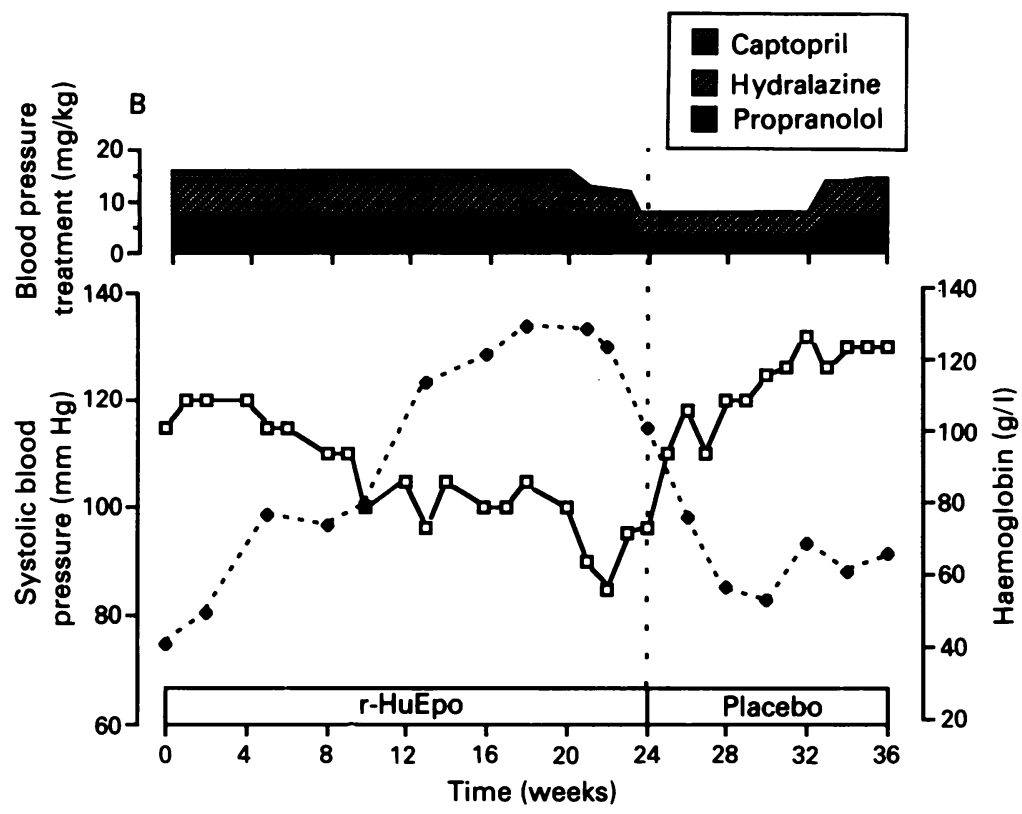

Figure 3 Changes in systolic blood pressure and haemoglobin in $(A)$ a child requiring an increase in antihypertensive treatment during treatment with $r-H u E$ po and $(B)$ a child requiring a reduction in antihypertensive treatment during treatment with $r-H u E p o$.

studies ( $<6$ months) have not shown a reduction in left ventricular wall thickness or left ventricular mass, ${ }^{411}$ while longer term studies have. ${ }^{59}$

The results of this study are therefore in agreement with adult studies of similar duration, showing a fall in cardiac index but only a trend towards a reduction in left ventricular hypertrophy, probably because the haemoglobin concentration was maintained above $100 \mathrm{~g} / \mathrm{l}$ for a mean of only 11 weeks. A significant reduction in left ventricular hypertrophy may follow a longer period of treatment.

Cardiac index fell as a result of a fall in left ventricular stroke volume and heart rate. We have previously attributed the high cardiac index found in these children to an increase in left ventricular stroke volume rather than heart rate, because heart rate was found to lie within a normal age matched range. ${ }^{2}$ The present study suggests that both make a contribution. The increase in cardiac index in anaemia is a consequence of poor tissue oxygenation, leading to compensatory peripheral vasodilation. Cropp showed that administration of oxygen to nonuraemic anaemic children partially reverses peripheral vasodilatation and leads to a reduction in cardiac index. ${ }^{14}$ Similarly, in patients with end stage renal failure, correction of anaemia by transfusion or $r$-HuEpo increases peripheral vascular resistance and decreases cardiac index, while improving tissue oxygenation. ${ }^{15}$ Changes in cardiac index are not due to a change in total blood volume, which is unaltered by $\mathrm{r}-\mathrm{HuEpo}$ treatment; an increase in red cell mass being balanced by a decrease in plasma volume. ${ }^{9}$

The fall in left ventricular end diastolic diameter after r-HuEpo is probably the consequence of a fall in left ventricular stroke volume, a common finding with adult studies. ${ }^{51011}$ Likewise the reduction in shortening fraction is more likely to reflect changes in stroke volume and left ventricular end diastolic diameter, rather than a real deterioration in myocardial contractility.

Hypertension can theoretically be due to an increase in cardiac output ${ }^{17}$ or an increase in peripheral vascular resistance. ${ }^{16}$ Ledingham $e t$ al have suggested that an increase in cardiac output underlies all hypertension, eventually stimulating a sustained increase in peripheral arteriolar resistance, with a return of cardiac output to normal. ${ }^{17}$

Patients with end stage renal failure with anaemia and hypertension have a high cardiac output, which could, in theory, contribute to hypertension. In the majority of patients, however, correction of anaemia leads to a fall in cardiac output without a corresponding fall in blood pressure, suggesting that an increase in peripheral vascular resistance is the predominant factor in most cases. The development, or exacerbation, of hypertension has been the commonest and most worrying side effect of $\mathrm{r}$-HuEpo administration, on occasions leading to encephalopathy.$^{18}$ Risk factors appear to be preexisting hypertension at the start of treatment, and the rate of rise of haemoglobin rather than the absolute level reached. We elected to increase haemoglobin slowly, but one child required a marked increase in antihypertensive treatment on $\mathrm{r}-\mathrm{HuEpo}$, despite a fall in cardiac index (6.9 to $\left.4.5 \mathrm{1} / \mathrm{min} / \mathrm{m}^{2}\right)$. After switching to placebo her blood pressure fell and treatment was reduced again (fig 3A). A minority of patients are reported to show a fall in blood pressure on r-HuEpo; one child, with a particularly high cardiac index $\left(12.6 \mathrm{1} / \mathrm{min} / \mathrm{m}^{2}\right)$, required a marked reduction in antihypertensive treatment during the r-HuEpo limb, followed by an increase during the placebo limb once his haemoglobin had fallen, and his cardiac index increased again (fig 3B). This suggests that an increased cardiac output contributes to hypertension in some patients. None of six previously normotensive children needed to start antihypertensive treatment while on r-HuEpo, and no significant change in blood pressure occurred. Although there is currently no way of predicting an 
individual's blood pressure response to r-HuEpo at the time of starting treatment, the height of the cardiac output may prove to be of value. Children with hypertension associated with a very high cardiac output may be more likely to show a fall in blood pressure with r-HuEpo, while those with hypertension and a lower cardiac output, in whom peripheral vascular resistance is higher, may be more likely to develop an increase in blood pressure on r-HuEpo. Careful monitoring of blood pressure is essential, particularly during the induction phase in patients with pre-existing hypertension.

In this study r-HuEpo treatment for 24 weeks led to a fall in cardiac index in a group of children with end stage renal failure and anaemia. This was as a result of a reduction in both heart rate and stroke volume. Further study is needed to determine whether a sustained reduction in cardiac workload will, in time, result in a significant reduction in left ventricular hypertrophy.

We are grateful to the staff of Clinic $\mathrm{E}$ and the electrocardiography department, Freeman Hospital for their help with the study, and to Boehringer Mannheim UK for supplying the erythropoietin for the study. Dr K P Morris and Dr J R Skinner are research fellows in child health supported by Newcastle District Research Heart Research Fund (JRS).

1 Broyer M, Brunner FP, Brynger H, Fassbinder W, Guillou $P J$, Oules R. Demography of dialysis and transplantation in Europe 1984. Report of the registry. Nephrol Dial Transplant 1986; 1:9-15.

2 Morris KP, Skinner JR, Wren C, Hunter S, Coulthard MG. Cardiac abnormalities in end stage renal failure and anaemia. Cardiac abnormalities in end stage

3 Neff MS, Kim KE, Persoff M, Onesti G, Swartz C. Hemodynamics of uremic anemia. Circulation 1971; 43: 876-83.
4 Teruel JL, Pascual J, Jimenez M, et al. Hemodynamic changes in hemodialysis patients during treatment with recombinant in hemodialysis patients during treatment with reco

5 Pascual J, Teruel JL, Moya JL, Liano F, Jimenez-Mena M, Ortuno J. Regression of left ventricular hypertrophy afte partial correction of anaemia with erythropoietin in patients on haemodialysis; a prospective study. Clin Nephrol 1991 35: $280-7$.

6 Coulthard MG, Sharp J. PROD: peritoneal rapid overnight dialysis in children. Pediatr Nephrol 1989; 3: C218.

7 Robson SC, Murray A, Peart I, Heads A, Hunter S. Reproducibility of cardiac output measurement by cross sectional and Doppler echocardiography. Br Heart f 1988; 59: 680-4.

and Doppler echocardiography. Br Heart f 1988; 59: 680-4. methods in medical research. 2nd Ed. London: Blackwell methods in medical research. 2nd Ed.

9 Cannella G, La Canna G, Sandrini M, et al. Renormalization of high cardiac output and of left ventricular size following long-term recombinant human erythropoietin treatment of anemic dialysed uremic patients. Clin Nephrol 1990; 6: 272-8.

10 London GM, Zins B, Pannier B, et al. Vascular changes in hemodialysis patients in response to recombinant human erythropoietin. Kidney Int 1989; 36: 878-82.

11 Tagawa $H$, Nagano $M$, Saito $H$, Umezu M, Yamakado $M$. Echocardiographic findings in hemodialysis patients treated with recombinant human erythropoietin: proposal for a with recombinant human erythropoietin: proposal for a hematocrit most

12 Low I, Grutzmacher P, Bergmann M, Schoeppe W. Echocardiographic findings in patients on maintenance hemodialysis substituted with recombinant human erythropoietin. Clin Nephrol 1989; 31: 26-30.

13 Verbeelen D, Bossuyt A, Smitz J, Herman A, Dratwa M, Jonckheer MH. Hemodynamics of patients with renal failure treated with recombinant human erythropoietin. Clin Nephrol 1989; 31: 6-11.

14 Cropp GJA. Hemodynamic responses to oxygen breathing in children with severe anemia. Circulation 1969; 40: 493-500.

15 Nonnast-Daniel B, Deschodt G, Brunkhorst R, et al. Longterm effects of treatment with recombinant human erythropoietin on haemodynamics and tissue oxygenation in patients with renal anaemia. Nephrol Dial Transplant 1990; 5: 444-8.

16 Brod J, Fencl V, Hejl Z, Jirka J, Ulrych H. General and regional hemodynamic pattern underlying essential hypertension. Clin Sci 1962; 23: 339-49.

17 Ledingham JM, Cohen RD. Circulatory changes during the reversal of experimental hypertension. Clin Sci 1962; 22: 6977 .

18 Edmunds ME, Walls J, Tucker B, et al. Seizures in haemodialysis patients treated with recombinant human erythropoietin. Nephrol Dial Transplant 1989; 4: 1065-9. 